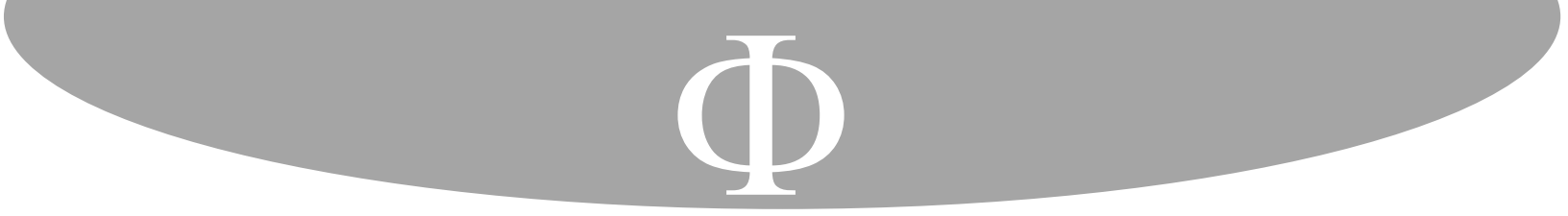

\title{
Autoconservación y trabajo desde la perspectiva edificante de Kierkegaard. Análisis de Lo que aprendemos de los lirios del campo y las aves del cielo (1847)*
}

Para citar este artículo: Rodríguez, Pablo Uriel. «Autoconservación y trabajo desde la perspectiva edificante de Kierkegaard. Análisis de Lo que aprendemos de los lirios del campo y las aves del cielo (1847)».

Franciscanum 175, Vol. 63 (2021): 1-23.

\section{Resumen}

El presente artículo discute los conceptos de «autoconservación» y «trabajo» en $L o$ que aprendemos de los lirios del campo y las aves del cielo. El análisis del discurso edificante escrito por Kierkegaard en 1847 permite definir la perspectiva que el danés asume ante el proyecto filosófico de la Modernidad. A partir de una crítica a las concepciones estéticas y éticas de la vida, el autor edificante propone un modelo de existencia religiosa que combina la autoconservación y la dependencia.

\section{Palabras Clave}

Kierkegaard, auto-conservación, trabajo, edificación, modernidad.

\section{Self-preservation and work from the edifying perspective of Kierkegaard. Analysis of What we learn from the lilies of the field and the birds of the sky (1847)}

\begin{abstract}
The present article deals with the concepts of «self-preservation» and «work» as we learn from the lilies of the countryside and the birds on the sky. The analysis of the exemplary discourse written by Kierkegaard in 1847 enables us to define the perspective that the Danish assumes in relation to the philosophical project of Modernity. The edifying author proposes

\footnotetext{
${ }^{*}$ El presente escrito es resultado de la investigación en torno a la figura de S. Kierkegaard desarrollada dentro del Programa de Investigación en Filosofía Posthegeliana del Instituto de Ciencias de la Universidad Nacional de General Sarmiento (UNGS, Argentina). La preparación inicial del texto coincide con la finalización de la Beca Postdoctoral otorgada por CONICET (Argentina).

** Doctor en Filosofía por la Universidad de Morón y Profesor en Filosofía por la Universidad de Buenos Aires (UBA). Es Profesor Adjunto de las materias «Filosofía Social y Teorías Políticas» y «Metafísica» de la Universidad de Morón. Es Docente de postgrado de la UBA en la materia "Filosofía Contemporánea" del Programa de Actualización de Filosofía. Se desempeña como Coordinador de Edición del Programa de Investigación en Filosofía Posthegeliana del ICI de la UNGS. Fue Becario Doctoral y Postdoctoral del CONICET (Argentina). Contacto: blirius@ hotmail.com. ORCID: https://orcid.org/0000-0002-8409-1610.
} 


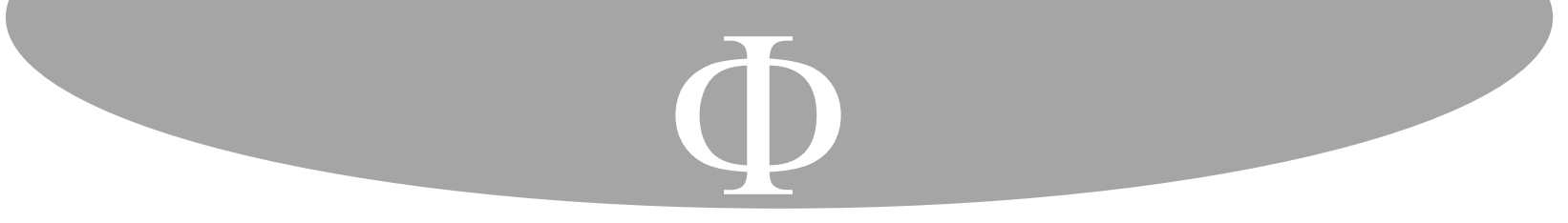

de estos textos. Si nos atenemos al significado más técnico y preciso con el que Kierkegaard se sirve del término danés «opbyggeligt» hay que reconocer que su empleo habitual entre los intérpretes y comentariasta incurre en una típica sinécdoque: cierto es que las obras edificantes son religiosas, pero no todas las obras religiosas son edificantes. La delimitación más exhaustiva de aquello que ha de entenderse estrictamente como un escrito edificante es desarrollada en el Postscriptum en los términos de una reflexión sobre los discursos publicados por el Magister Kierkegaard durante 1843 y 1845.

Al autor pseudónimo Climacus le interesa responder la siguiente pregunta: ¿por qué el Magister Kierkegaard llama con total propiedad a sus escritos discursos y no sermones? El pseudónimo no hace más que llamar la atención de sus lectores sobre la aclaración que el mismo Kierkegaard introduce al comienzo de los «Prefacios» ${ }^{10}$ : el texto lleva el título de discurso y no de sermón (Pradiken) porque a su autor no se le ha concedido la autoridad necesaria para predicar ${ }^{11}$. Sin embargo, el tratamiento del pseudónimo no se detiene en esta distinción externa al texto y avanza en función de un análisis de su contenido. De acuerdo con Climacus, en tanto y en cuanto se quiera utilizar el lenguaje con corrección terminológica y evitar malentendidos babélicos, el término «sermón» deberá reservarse para la expresión de todo aquello vinculado con la existencia cristiana. Los escritos religiosos del Magister Kierkegaard, por su parte, echan mano de las categorías éticas de la inmanencia y no de las paradójicas categorías cristianas ${ }^{12}$ :

Pese a que [en los Discursos Edificantes] se afirma el requerimiento de lo ético, pese a que la vida y la existencia se acentúan como un difícil camino, de cualquier forma no se introduce la decisión en la paradoja... La expresión paradójica de la existencia (esto es, el existir), como pecado, la verdad eterna que se vuelve paradoja al devenir en el tiempo, en suma, aquello que es decisivo para lo cristiano-religioso, es algo que no puede encontrarse en los discursos edificantes (...) Lo más seguro es que Magister Kierkegaard sabía lo que hacía cuando llamó Discursos Edificantes a los discursos edificantes, y sabía también la razón por la que se abstuvo de utilizar categorías dogmático-cristianas, de mencionar el nombre de Cristo, etc., lo cual de todos modos se hace en nuestra época con entera libertad, pese a que las categorías, los pensamientos, los elementos dialécticos en la exposición, etc., son sólo aquellos de la inmanencia ${ }^{13}$.

La tarea de lo edificante es mostrar cuál es el límite de la reflexión filosófica ${ }^{14}$. Este non plus ultra de la razón humana es lo que el autor del Postscriptum denomina Religiosidad

\footnotetext{
${ }^{10}$ Estas líneas iniciales se repiten en todos los «Prefacios» de las obras denominadas «edificantes»: en las seis series que contabilizan un total de 18 discursos publicados entre 1843-1844, en la colección de tres escritos titulada Discursos edificantes en diversos espíritus de 1847 y en Un discurso edificante del año 1850.

${ }^{11}$ Søren Kierkegaards Skrifter 5: 13 / Søren Kierkegaard, Discursos Edificantes. Tres discursos para ocasiones supuestas, Vol. 5 (Madrid: Trotta, 2010), 29.

${ }^{12}$ Cf. Søren Kierkegaards Skrifter 7: 233 / Søren Kierkegaard, Postscriptum no científico y definitivo a Migajas filosóficas (México: Universidad Iberoamericana, 2009), 258-259.

${ }^{13}$ Søren Kierkegaards Skrifter 7: 247 / Søren Kierkegaard, Postscriptum no científico y definitivo a Migajas filosóficas, 273-275.

${ }^{14}$ Cf. Søren Kierkegaards Skrifter 7: 233 / Søren Kierkegaard, Postscriptum no científico y definitivo a Migajas filosóficas, 259.
} 


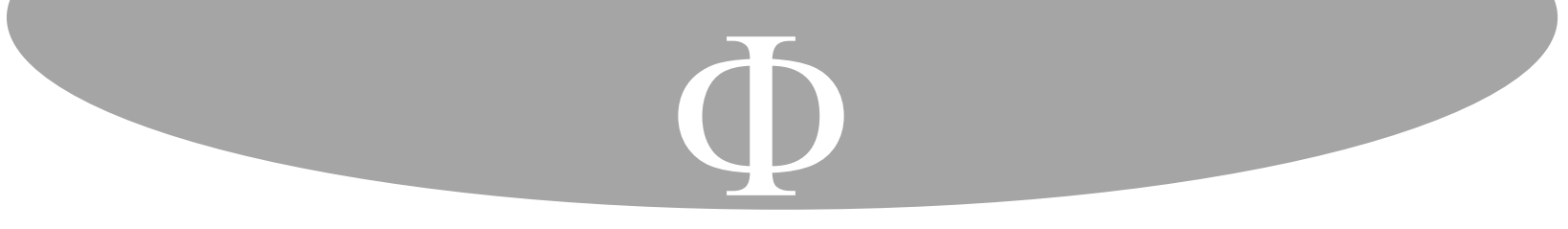

comunicativo que tenga como objetivo último la constitución de la libertad del otro: salir al encuentro del interlocutor allí donde éste se encuentra ${ }^{25}$.

Por qué razón, en qué medida y en qué sentido una individualidad religiosa precisa de un consuelo edificante son cuestiones enigmáticas que dejaremos sin abordar en nuestra presentación para focalizarnos en el impacto que el mensaje evangélico puede producir en la existencia estética y en la ética. El autor pseudónimo del Postscriptum había utilizado el par conceptual dependencia (poseer el fundamento del propio ser fuera de sí) e independencia (afirmar el sí mismo como fundamento del propio ser) para caracterizar la contraposición entre las concepciones estética y ética de la existencia ${ }^{26}$. Esta dicotomía conceptual le permitía a Climacus resumir el recorrido de la heteronomía a la autonomía descripto en las dos partes de $O$ lo uno o lo otro: desde el esteticismo ingenuo que busca en los diversos objetos del mundo la plena realización de la personalidad y a través del programa estético reflexivo de una configuración artística de la realidad a expensas de la genialidad poética hasta la apropiación ética de la propia libertad como centro configurador de la existencia por medio de la auto-elección. El propósito edificante consiste en mostrar la inconsistencia de estos proyectos y la necesidad de su superación. Kierkegaard disuelve la disyunción excluyente de su primer libro pseudónimo y propone una alternativa radical más profunda y verdadera: la elección que realmente define la vida humana no es la de apoyar el propio ser en el mundo o apoyarlo sobre el yo sino la de fundar nuestra existencia o no en Dios. «Fundarse en Dios» implica, desde ya, el abandono del proyecto ético que pretendía convertir al yo en el centro absoluto de la existencia. Pero «fundarse en Dios» tampoco puede supone un retorno sin más a lo estético, puesto que si así lo fuese el pasaje de lo estético a lo religioso sería un mero cambio de objeto. No se trata únicamente de descansar en Dios en lugar de hacerlo en otra cosa, sino también -y quizás más fundamentalmente- de modificar el modo en que optamos y el modo en que nos remitimos con aquello que está fuera de nuestro ser. De modo que, el discurso edificante no solo "revalida" lo estético frente a lo ético sino que también "corrige" lo estético a través de lo ético.

\subsection{La conciencia preocupada por su finitud}

La meditación sobre los lirios del campo y las aves del cielo pretende servir de orientación y consuelo para individuos desdichados. La parte inicial del discurso distingue dos tipos fundamentales de aflicciones. La primera clase de aflicción tiene como condición de posibilidad la participación del individuo en un grupo social. Kierkegaard la llama «preocupación mundana» (verdslig Bekymring) o «preocupación temporal» (timelig Bekymring) y la considera más cercana a lo femenino. La segunda clase de aflicción, denominada «cuidado del sustento» (Naringssorg) ${ }^{27}$, es previa a la naturaleza social del

\footnotetext{
${ }^{25}$ Cf. Søren Kierkegaards Skrifter 16: 27-29 / Søren Kierkegaard, Mi punto de vista (Buenos Aires: Aguilar, 1959), 56-60.

${ }^{26}$ Cf. Søren Kierkegaards Skrifter 7: 519 / Søren Kierkegaard, Postscriptum no científico y definitivo a Migajas filosóficas, 573.

${ }^{27}$ Literalmente es el cuidado por la nutrición o alimentación. La traducción inglesa de los Hong opta por la expresión «making a living» - «ganarse la vida».
} 


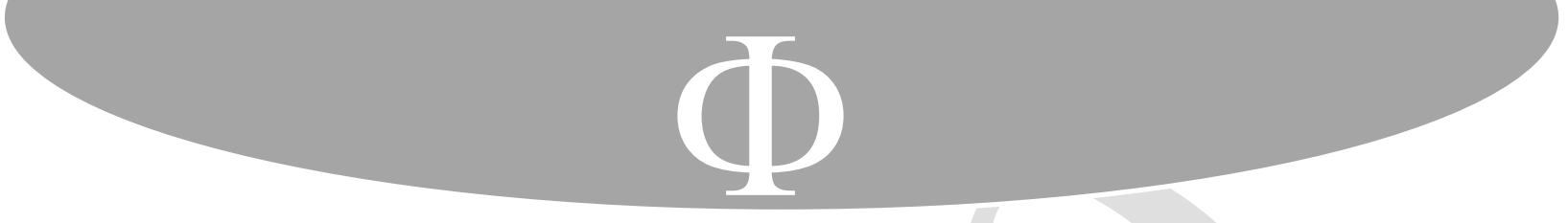

hombre y se revela más afín al varón ${ }^{28}$. La preocupación mundana consiste en el sentimiento de inferioridad que se apodera del individuo cuando compara su situación con la de sus semejantes. El cuidado del sustento equivale a la serie de recaudos que toma el individuo cuando al adquirir conciencia de sus necesidades básicas es embargado por una sensación de inseguridad e incertidumbre. Para ambos tipos de inquietud la solución propuesta por Kierkegaard es una y la misma «conformarse con ser hombre», pero el sentido concreto de esta recomendación varía en cada caso.

En el caso de la preocupación mundana, el conformarse con ser hombre se dirige contra ese anhelo de excepcionalidad que surge en el individuo en la medida en que siendo miembro de una comunidad sólo puede validar su identidad comparándose con quienes lo rodean para diferenciarse de ellos. El reconocimiento público otorgado al individuo traduce su desempeño dentro de la esfera de competencia social, por lo cual, la medida de evaluación del yo depende tanto del éxito de su actividad como del juicio explícito o implícito de los demás. Toda estima de sí queda sujeta a una doble contingencia instalando al ser humano en una situación de vulnerabilidad e incertidumbre y a merced del auto-desprecio. Resuena aquí cierto eco de la crítica de Rousseau a la sociedad moderna: el afán de prestigio se convierte en la orientación última de toda conducta pervirtiendo el correcto entendimiento de sí mismo $^{29}$. Con este análisis, el discurso edificante anticipa un tópico de La enfermedad mortal puesto que Kierkegaard advierte que al ser presa de la preocupación mundana el yo abandona su propia identidad para ser otro y al comportarse de este modo interpone en su relación consigo mismo una medida que malogra dicha relación ${ }^{30}$. Frente a esto, el texto del discurso

\footnotetext{
${ }^{28}$ Para un análisis sobre los tipos de preocupación desde una perspectiva del género asignado a ellas por Kierkegaard se puede consultar: Silvia Walsh, «If the Lily could speak: On the contentment and glory of being human» en International Kierkegaard Commentary: Upbuilding Discourses in various Spirits, ed. Robert Perkins (Georgia: Macon University Press, 2005), 129-152.

${ }^{29}$ El antecedente más cercano de Kierkegaard es el análisis de la sociedad capitalista industrial que Hegel desarrolla bajo la exposición del «sistema de las necesidades» en sus Principios de la Filosofía del Derecho. El esfuerzo del individuo no se encamina a la mera satisfacción de una necesidad biológica sino, más bien, al cumplimiento de un deseo. Cf. Georg Hegel, Principios de la Filosofía del Derecho (Barcelona: Edhasa, 1999), 314 Agr. $§ 190$. Pero este deseo no tiene un origen estrictamente individual, sino que está condicionado por el gusto y la opinión de los otros, cf. Agr. $§ 192$. La vida social torna necesarios determinados consumos porque realizarlos es un medio para igualarse a los demás. Frente a este descentramiento del individuo que Rousseau concebía como un signo de la decadencia; Hegel asume una posición ambivalente. Por una parte, no deja de denunciar los peligros y miserias inherentes a la organización económica burguesa (cf. $§ 185$ ) pero, por otra parte, considera que la dialéctica de las necesidades es un momento necesario del desarrollo espiritual del mundo ético. La multiplicación y el refinamiento de las necesidades y la búsqueda generalizada de la estima social exige una cooperación social más intensa y una optimización de la actividad individual basada en la razón, cf. § 194.

${ }^{30}$ Cf. Søren Kierkegaards Skrifter 8: 268-269 / Søren Kierkegaard, «Lo que aprendemos de los lirios del campo y de las aves del cielo», en Los lirios del campo y las aves del cielo (Madrid: Guadarrama, 1963), 49. Iben Damgaard indica claramente como esta temática será recuperada poco tiempo después al meditar en torno al fenómeno del amor cristiano: «[En Las obras del amor], Kierkegaard argumenta que para llegar a ser sí mismo, el ser humano necesita diferenciarse de la multitud en la cual él se mira a través de los ojos de los demás y se reduce a aquello que «los otros» hacen de él y a aquello que él hace de sí mismo al existir únicamente ante los otros». Iben Damgaard, «The danger of “the Restless Mentality of Comparison”. Kierkegaard's Parables of the
} 


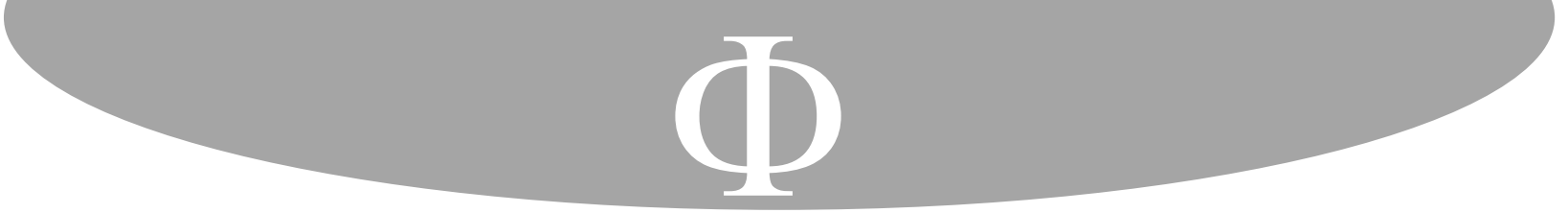

edificante argumenta que existe una significación individual originaria que no está condicionada por ningún logro o mérito individual ni tampoco por ningún reconocimiento externo, sino que depende del mero hecho de ser lo que se es. El yo, dice el danés, «sin trabajar, sin hilar, sin ningún mérito propio, por el solo hecho de ser hombre, [es] más glorioso que la gloria de Salomón» puesto que «ser un hombre no es inferior a las diferencias, sino algo superior a las mismas» ${ }^{31}$.

La reflexión en torno a la preocupación provocada por el cuidado del sustento se enfrenta con un fenómeno cualitativamente diferente. El danés se guarda muy bien de recusar esa ego-centralidad inmediata y natural sin la cual cualquier tipo de vida sería inviable. Frater Taciturnus, uno de los múltiples autores pseudónimos de Etapas en el camino de la vida, ya había señalado que la salud natural está sujeta al impulso de autoconservación (Selvopholdelsens Drift). Sin embargo, resulta erróneo derivar preceptos morales de esta tendencia inmediata sin considerar que en el ser humano dicha orientación debe ser reconfigurada por la reflexión -equivocación en la cual incurrió el estoicismo ${ }^{32}$. Asumiendo la autopreservación como un dato básico de la existencia, el tema principal del discurso edificante pasa a ser la clase de posicionamiento existencial que debe asumir el individuo frente a la búsqueda de aquellas condiciones materiales básicas que garantizan la continuidad de su ser. Del tratamiento efectuado por Kierkegaard puede concluirse que la satisfacción de ciertas necesidades materiales es, desde luego, un requerimiento ineludible para la prolongación de la vida pero, al mismo tiempo, constituye la oportunidad para un deleite completamente lícito de lo temporal. Justamente, la consecuencia más inmediata de la inquietud generada por el cuidado del sustento radica en la cancelación de ese goce. Lo que perturba al individuo no es una privación real sino una penuria imaginada ${ }^{33}$. Esta conciencia de una eventual carencia futura se transforma en un obstáculo prácticamente insalvable para el disfrute que debería acompañar la satisfacción presente de una necesidad ${ }^{34}$. A la conciencia

Lily and the Bird», en Kierkegaard Studies Yearbook, eds. Niels Jørgen Cappelørn, Hermann Deuser y Brian Söderquist (Berlin: De Gruyter, 2007), 199-200.

${ }^{31}$ Søren Kierkegaards Skrifter 8: 265 y 270 / Søren Kierkegaard, «Lo que aprendemos de los lirios del campo y de las aves del cielo», 44 y 51.

${ }^{32}$ Cf. Søren Kierkegaards Skrifter 6: 400 / Søren Kierkegaard, El amor y la religión (Buenos Aires: Andrómeda, 2006), 84.

${ }^{33}$ Kierkegaard retoma esta distinción hegeliana alterando por completo la perspectiva de análisis. Mientras que Hegel veía este pasaje de la necesidad real a la necesidad representada como una consecuencia inevitable de la complejización económica de la sociedad y una oportunidad para el desarrollo de la esencia humana, Kierkegaard le atribuye este pasaje a una «decisión» que distorsiona la autorrelación individual.

${ }^{34}$ Cf. Søren Kierkegaards Skrifter 8: 274 / Søren Kierkegaard, «Lo que aprendemos de los lirios del campo y de las aves del cielo», 57. Kangas sostiene que el discurso edificante nos advierte que en la preocupación por la subsistencia el presente queda vaciado de significado a expensas de la proyección existencial hacia el futuro, puesto que lo meramente imaginario ocupa el lugar de lo auténticamente real. Cf. David Kangas, «Being Human: Kierkegaard's 1847 Discourses on the Lilies of the Field and the Birds of the Air», Konturen 7 (2015): 3 - 4. El consejo edificante, por tanto, sería ir más allá del orden de la representación para retornar a la realidad. Se trataría, por tanto, de hacer a un lado todo proyecto surgido de nuestra propia voluntad con el cual pretendemos controlar el acontecer del mundo y abrazar la idea de que solo existe auténticamente quien vive sin un por qué. Cf. David Kangas, «Being Human: Kierkegaard’s 1847 Discourses on the Lilies of the Field and the Birds of the Air»: 12-13. De opinión semejante es Garrido Maturana, para quien la meditación edificante de Kierkegaard opera una suerte de inversión temporal de la esperanza: el objetivo de la esperanza no es 


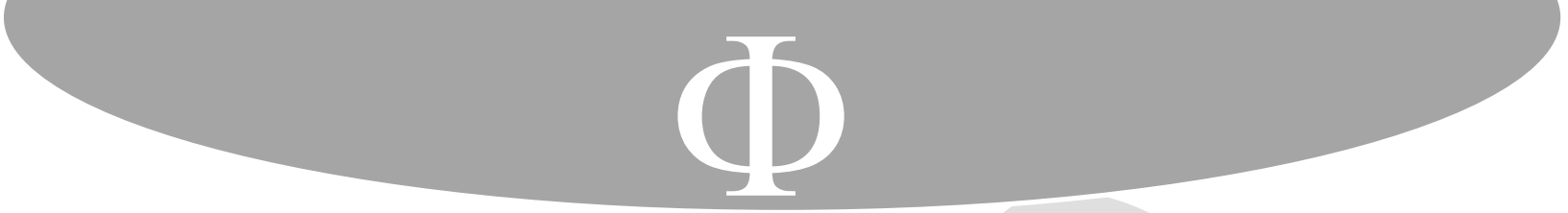

la medida en que el ser humano es tiempo, es decir, está en devenir; al relacionarse consigo mismo se relaciona, desde ese sí mismo que él está siendo, con el sí mismo que ha sido y con el que será ${ }^{42}$. El instante es el ahora de la actividad del espíritu en el cual el individuo existente adquiere una acabada conciencia de los límites y las condiciones de posibilidad de su proyecto existencial: primeramente, comprende que su estar siendo depende de su haber sido; a su vez, comprende que su haber sido no define completamente su estar siendo y, por último, comprende fundamentalmente que lo que él será no puede ser concebido como una mera continuidad de lo que está siendo ${ }^{43}$.

En el discurso edificante de 1847 puede leerse que gracias al contacto entre el tiempo y la eternidad el ser humano descubre el porvenir, esto es, se hace consciente de que en última instancia el futuro es una realidad que nunca está por entero a su disposición ${ }^{44}$. De la incertidumbre que genera el porvenir, de esta angustia ante lo futuro, nace la preocupación por la subsistencia ${ }^{45} \mathrm{y}$, acto seguido, surge la forma errónea de enfrentarse con esta aflicción que Kierkegaard censura. Al adquirir conciencia del carácter abrumador y amenazante del porvenir el individuo pretende controlar completamente la eventualidad del futuro a través de la actividad presente: quiere configurar a partir del día de hoy el día de mañana. Pero dado que el individuo no puede dejar de experimentar y reconocer que el futuro siempre excede su anticipación previsora y sus fuerzas, esta pretensión es un proyecto desesperado que se sostiene mientras sea efectivo un profundo auto-engaño.

¿Cómo debe lidiar el ser humano con la preocupación por la subsistencia? Los lirios del campo y las aves del cielo no constituyen un modelo adecuado para resolver su situación

la eternidad como un tiempo infinito. Entendida de este último modo, la eternidad adquiere para el existente el sentido de una carga terrorífica. El rechazo manifiesto del desesperado a la naturaleza inmortal de su espíritu, esto es, su horrorizarse ante el hecho de no poder desentenderse de su tener que ser. Cf. Søren Kierkegaards Skrifter 11: 136 / Søren Kierkegaard, La enfermedad mortal (Madrid: Sarpe, 1984), 46-47, es consecuencia directa del modo en que la conciencia desdichada comprende y experimenta la eternidad: una duración sin reposo ni fin.

42 Dado que no ha sido el yo quien se ha emplazado en esta situación, su carácter eterno, en última instancia, le viene dado por aquel Poder que lo ha puesto en esa actividad autorreferencial que él es.

${ }^{43}$ Walter Schulz afirma que, en la temporalidad existencial constituida por el instante, por una parte, el futuro al cual accedemos no es puro en la medida en que las posibilidades que él abre están definidas por el pasado pero, por otra parte, tampoco el pasado está absolutamente cancelado en la medida en que queda abierto a su repetición. Cf. Walter Schulz, «Die Dialektik von Geist und Leib bei Kierkegaard. Bemerkungen zum "Begriff Angst"», en Materialien zur Philosophie Sфren Kierkegaards, eds. Michael Theunissen y Wilfried Greve (Frankfurt am Main: Suhrkamp Verlag, 1979), 352. Si bien es cierto que el pasado configura el futuro, éste último desborda esta configuración al punto de poder recuperar lo que el pasado había cancelado.

${ }^{44}$ Cf. Søren Kierkegaards Skrifter, 8: 292 / Søren Kierkegaard, «Lo que aprendemos de los lirios del campo y de las aves del cielo», 83 .

${ }^{45}$ La conciencia de esta fragilidad es un signo distintivo de lo humano a punto tal que únicamente puede constituirse en medida del hombre quien posee efectivamente esta conciencia. Dicho con las palabras del pseudónimo Johannes Climacus en sus Migajas Filosóficas: Dios se hace efectivamente humano si asume la finitud al punto de preocuparse por su subsistencia y superar esta preocupación de lo contrario Él habría adoptado ficcionalmente la forma humana. Cf. Søren Kierkegaards Skrifter, 4: 239 y 258-259 / Søren Kierkegaard, «Migajas Filosóficas o un poco de filosofía», en Escritos de Søren Kierkegaard Vol. 4/2 (Madrid: Trotta, 2016), 50 y 72 . 


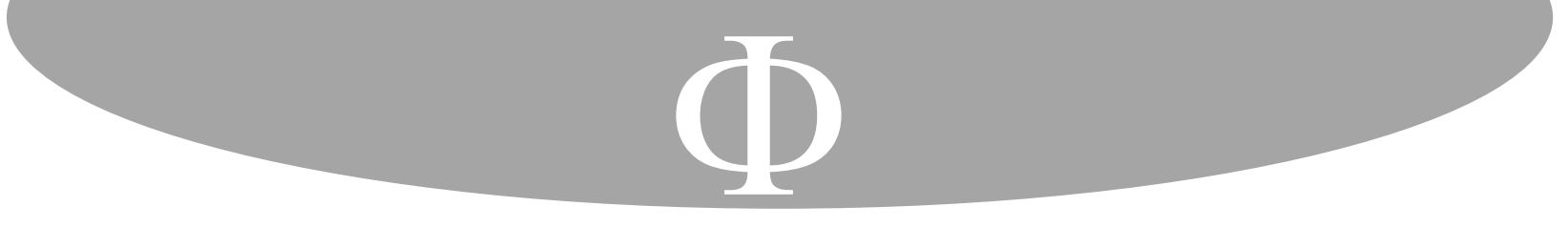

por la sencilla razón de que a diferencia del ser humano ellos no trabajan $^{46}$. ¿Qué significa específicamente el no trabajar de la naturaleza? Sirviéndose del texto evangélico (Mt 6, 26), Kierkegaard afirma que los pájaros no siembran, no siegan ni encierran en graneros. El no trabajar del pájaro no significa reposo, sino la ausencia de una actividad orientada conscientemente a partir de la diferenciación entre pasado, presente y futuro.

Llegado a este punto el discurso sobre los lirios y las aves retoma la discusión en torno a la noción de trabajo desarrollada cuatro años atrás en $O$ lo uno o lo otro a través de la disputa entre las concepciones estética y ética de la existencia. Agnes Heller indicó con agudeza que al desdoblar el tratamiento del trabajo en dos posiciones antagónicas Kierkegaard quedó en la antesala de una teoría consecuente del trabajo alienado, que solo alcanzaría su apropiada formulación con Karl Marx. Para el filósofo alemán el trabajo es desde el punto de vista teórico la base para la auto-creación del hombre, pero en la práctica, y ello en virtud de las condiciones sociales objetivas, no es más que una actividad alienada y alienante. En $O$ lo uno o lo otro, Kierkegaard expondría de manera preponderantemente literaria esta misma contradicción a través de la polémica entre las figuras existenciales encarnadas por el esteta A y el ético B: para el primero de ellos no hay trabajo alguno capaz de liberar al ser humano, para el segundo todo trabajo, sean cuales sean sus circunstancias con la única condición de ser correctamente elegido y ejecutado, es capaz de cumplir una función constitutiva y emancipatoria ${ }^{47}$.

La perspectiva estética de la vida asume una posición negativa frente al trabajo concibiéndolo como una actividad irreconciliable con su criterio normativo: el objetivo de disfrutar de las circunstancias vitales. El punto de partida del esteta A es la convicción de que la finalidad de un ser que ha sido dotado con las capacidades y habilidades que se le han otorgado al ser humano no puede ser la mera subsistencia. Por lo tanto, una actividad cuya meta es hacer posible la prolongación de la existencia adquiere valor y significado únicamente en función de la calidad de esa existencia a la cual procura preservar. El trabajo, por tanto, es un esfuerzo contradictorio ya que se trata de un medio que destruye su fin: trabajando el individuo consume el tiempo y la energía que debería destinar al embellecimiento de su existencia a través del goce. La apología ética del trabajo comienza reconociendo que si el asunto se plantea desde una perspectiva estética la recompensa que el hombre obtiene a través del trabajo resulta a todas luces insatisfactoria: la vida que se

\footnotetext{
${ }^{46}$ Al respecto Leo Stan sostiene que el magisterio que sobre el hombre puede ejercer el mundo natural es capaz de recordarnos una verdad religiosa, pero no de ofrecer un criterio normativo de acción. Aprender de los lirios y las aves no debe entenderse en los términos de un retroceso ontológico a un estado primitivo en el cual estemos al margen de los peligros inherentes a la civilización. Cf. Leo Stan, «The Lily in the Field and the Bird of the Air: an Endless Liturgy in Kierkegaard's Autorship», en Kierkegaard and the Bible. Tome II: The New Testament (Kierkegaard Research: Sources, Reception and Resources), eds. Lee Barrett y Jon Stewart (Ashgate: England, 2010), 58.

${ }^{47}$ Cf. Agnes Heller, «Fenomenología de la conciencia desdichada. Sobre la función histórica de La alternativa de Kierkegaard», en Crítica de la Ilustración (Barcelona: Ediciones Península, 1999), 170.
} 


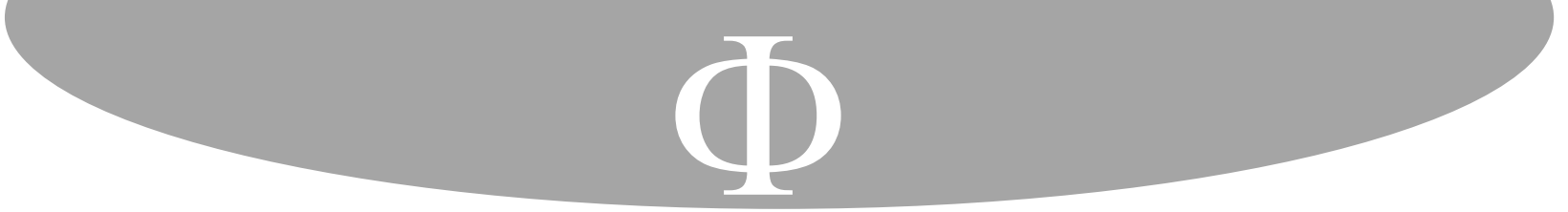

Resulta llamativo observar que en este pasaje Kierkegaard emplea contra el pseudónimo B un argumento similar al que aquel utiliza contra diversas variantes del esteticismo $^{53}$ : no estamos autorizados a concluir la ausencia de una «enfermedad» a partir de la mera ausencia de sus «síntomas».

Sin embargo, sería apresurado traducir todos estos señalamientos como un rechazo radical de la perspectiva ética y como la subsiguiente propuesta de una vida inoperante consagrada exclusivamente a la contemplación puesto que la segunda parte del discurso recupera ciertos aspectos de la posición ética edificantemente corregidos. La naturaleza, aquí representada por el suave florecer del lirio y el incansable ir y venir del ave, no colabora con los designios divinos, sino que se limita a ejecutarlos. La perfección intrínseca a la actividad natural consiste en no agregar nada a la voluntad de Dios. En el mundo natural, escribe Kierkegaard en sus discursos piadosos de $1849^{54}$, lo único activo es el querer soberano de Dios. El obrar de las criaturas naturales no difiere del mismo ser que Dios eligió para ellas ${ }^{55}$. Ahora bien, el ser que Dios ha dispuesto para el hombre le es entregado a éste para que sea aceptado de manera consciente y voluntaria por lo cual la actividad humana se diferencia sustancialmente de la actividad natural. A diferencia de lo que sucede con las criaturas naturales el hombre es ante sí mismo (posee consciencia) y por este motivo él, como sí pueden el lirio y el ave, no puede simplemente ser lo que es; entre el hombre y su ser existe una distancia irreductible. La existencia de un individuo que hiciese a un lado toda actividad autoconservadora sería imperfecta puesto que con esa renuncia también estaría renunciando a esa semejanza con Dios que distingue al ser humano del mundo natural. Correctamente entendida esta actividad puede ser un motivo lícito de orgullo porque a través de ella el hombre se transforma en aquello en lo cual ningún otro ser vivo se puede convertir: un colaborador de Dios (Guds Medarbeider $)^{56}$. El ser humano, por tanto, también es corresponsable de la preservación de su ser y no puede limitarse a descansar plácidamente en la acción sostenedora de un otro: «es precisamente una perfección eso de no ser toda la

\footnotetext{
${ }^{53}$ Cf. Søren Kierkegaards Skrifter 3, 186 / Søren Kierkegaard, «O lo uno o lo otro II. Fragmento de vida II», 177.

${ }^{54}$ A diferencia del discurso edificante, el discurso piadoso no antecede, sino que presupone la exigencia cristiana.

${ }^{55}$ Cf. Søren Kierkegaards Skrifter 11, 30 / Søren Kierkegaard, «El lirio en el campo y el pájaro bajo el cielo», en Los lirios del campo y las aves del cielo (Madrid: Guadarrama, 1963), 250. «La obediencia de la que habla Kierkegaard y que la naturaleza practica puntillosamente no es la obediencia a un código extrínseco al proceso mismo de ser, sino una obediencia tal que permite el desarrollo de las posibilidades finitas de aquel que obedece y las integra en un todo o configuración de sentido donde esas mismas posibilidades resultan consonantes con el desenvolvimiento, en última instancia, del cosmos... En de la esperanza, contra de una muy difundida lectura, que hace centro en la irracionalidad y el absurdo como motivos de la fe y de la esperanza, Kierkegaard, al menos en sus discursos edificantes, encuentra la obediencia a Dios y la esperanza en su reino no en los océanos que se abren, sino «en el flujo y reflujo de las mareas a horas fijas», no en el movimiento caprichoso de los astros, sino "en la rotación exacta de las estaciones", no en un sol que se vuelve tinieblas en medio del día, sino en "la puntual salida del sol, y en su puesta no menos puntual”». Ángel Garrido Maturana, «Un Nuevo amanecer. Lectura de la idea de esperanza en el pensamiento de S. Kierkegaard», 36.

${ }^{56}$ Cf. Søren Kierkegaards Skrifter 8, 294 / Søren Kierkegaard, «Lo que aprendemos de los lirios del campo y de las aves del cielo», 87 .
} 


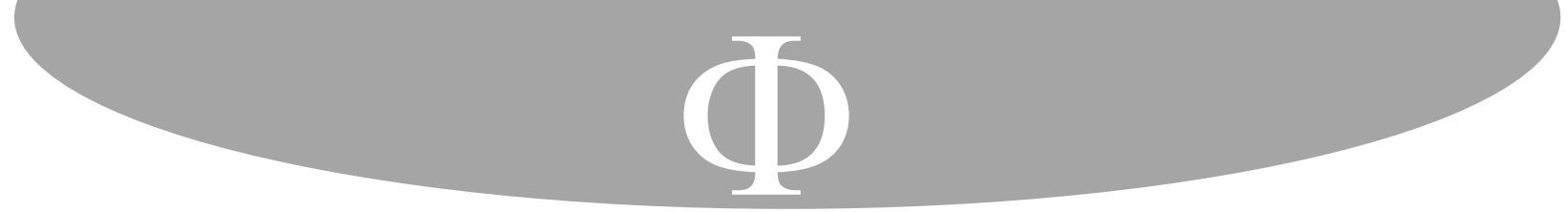

\section{Consideraciones finales}

Dos años después de la publicación del discurso sobre los lirios del campo y las aves del cielo, La enfermedad mortal emplea una célebre expresión para describir el único movimiento con el cual es posible superar la desesperación y alcanzar una existencia humana plena: el yo queriendo ser sí mismo debe fundar su existencia sobre aquella instancia trascendente de la cual ha recibido su propio ser. La afirmación conclusiva de la primera parte del escrito edificante, a saber, la verdadera independencia del yo implica su dependencia con respecto a Dios se desarrolla en la segunda parte conforme a una dialéctica similar a la expuesta en el capítulo inicial de la primera obra firmada por el autor pseudónimo Anti-Climacus: la conservación de sí lograda a través de la acción del trabajo encuentra su auténtico punto de apoyo en una realidad que excede, origina y acompaña la potencia individual $^{61}$.

Ambas fórmulas vislumbran una reconfiguración del principio moderno de autoconservación en sintonía con el entendimiento cristiano de la realidad humana desplegado en la filosofía del danés. La característica fundamental de esta reelaboración radica en su congruencia con la autoconciencia existencial del yo a partir de la cual Kierkegaard concluye el carácter derivado del sí mismo. A través de la serie de intentos con los cuales el yo pretende equilibrar las tensiones que constituyen su ser, éste se percata de que sus fuerzas tropiezan una y otra vez con límites internos y, a través de esta experiencia, se manifiestan insuficientes para alcanzar su proyecto. En el ejercicio mismo de su poder el yo queda enfrentado a una perturbadora y extraña dimensión de sí mismo irreductible a su capacidad. Esta es la experiencia que le permite a Anti-Climacus afirmar que al habérselas consigo mismo el sí mismo queda referido a otro. Desde un punto de vista estrictamente inmanente, postular el «estar-puesto del yo» implica afirmar que éste no tiene en sí mismo su fundamento. Siendo derivado el yo es incapaz de disponer completa y voluntariamente de las condiciones que definen su ser ya que si fuese propietario de un poder capaz de

\footnotetext{
${ }^{61}$ Nos permitimos señalar una característica peculiar del modo en que Kierkegaard discute el principio moderno de la autoconservación en su tratado psicológico sobre la desesperación. En Lo que aprendemos de los lirios del campo y las aves del cielo Kierkegaard aborda el problema de la conservación de la existencia en una perspectiva eminentemente material: el tema es la continuidad biológica de un individuo pre-existente al acto de su conservación. En La enfermedad mortal la cuestión de la conservación del individuo se enfoca desde una perspectiva psicológico-espiritual y, por este mismo motivo, ya no se trata sobre la perduración de un sí mismo previamente constituido sino del proceso de formación del mismo. Cf. Wolfhart Pannenberg, Antropología en perspectiva teológica. Implicaciones religiosas de la teoría antropológica, 124. En la medida en que La enfermedad mortal define toda circunstancia vital o bien como desesperación, esto es, como una situación de autodestrucción del yo; o bien como superación de la desesperación, es decir, como una realización del yo a través de la fe, es necesario afirmar que en la teoría de la personalidad de Anti-Climacus la conservación y la constitución del sí mismo quedan indisolublemente ligados. El punto de partida de la actividad configuradora del espíritu no es una realidad sino una posibilidad y, por ello, el pseudónimo puede afirmar que el ser humano «no es sí mismo mientras no se haga a sí mismo». Søren Kierkegaards Skrifter 11: 146 / Søren Kierkegaard, La enfermedad mortal, 59. Dado que, al principio del libro, el ser humano se identifica con el proceso mismo de autoconfiguración de la singularidad está en lo cierto Heiko Schulz cuando afirma que «el yo existe únicamente (y únicamente como él mismo) en la actividad por medio de la cual... se preserva», Heiko Schulz, Eschatologische Identität: Eine Untersuchung über das Verhältnis von Vorsehung, Schicksal und Zufall be Sören Kierkegaard (Berlin: De Gruyter, 1994), 271.
} 


\section{$\Phi$}

Weber, Max. La ética protestante y el «espíritu» del capitalismo. Madrid: Alianza, 2006.

Enviado: 27 de enero de 2020

Aceptado: 4 de abril de 2020

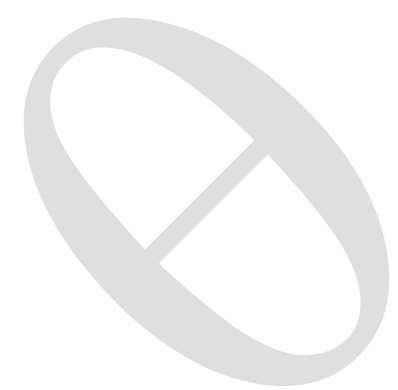

